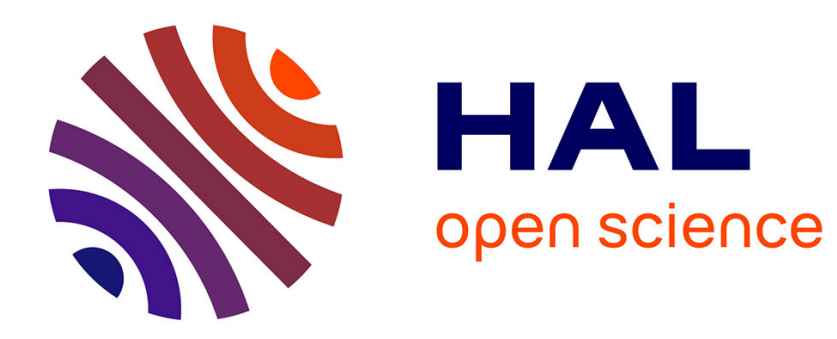

\title{
High Resolution Loss Spectroscopy of Quartz
}

R. Kant, C. Carosella, G. Hubler

\section{To cite this version:}

R. Kant, C. Carosella, G. Hubler. High Resolution Loss Spectroscopy of Quartz. Journal de Physique IV Proceedings, 1996, 06 (C8), pp.C8-837-C8-840. 10.1051/jp4:19968180 . jpa-00254617

\section{HAL Id: jpa-00254617 https://hal.science/jpa-00254617}

Submitted on 1 Jan 1996

HAL is a multi-disciplinary open access archive for the deposit and dissemination of scientific research documents, whether they are published or not. The documents may come from teaching and research institutions in France or abroad, or from public or private research centers.
L'archive ouverte pluridisciplinaire HAL, est destinée au dépôt et à la diffusion de documents scientifiques de niveau recherche, publiés ou non, émanant des établissements d'enseignement et de recherche français ou étrangers, des laboratoires publics ou privés. 
JOURNAL DE PHYSIQUE IV

Colloque C8, supplément au Journal de Physique III, Volume 6, décembre 1996

\title{
High Resolution Loss Spectroscopy of Quartz
}

\author{
R.A. Kant, C.A. Carosella and G.K. Hubler \\ Naval Research Laboratory, Washington, DC 20375, U.S.A.
}

\begin{abstract}
Naval Research Laboratory (NRL) scientists have developed an instrument that has extreme sensitivity to energy dissipation in mechanical resonators. While previous instruments measured loss to one part in ten, the new instrument measures mechanical loss to one part in $10^{4}$ or better. Low defect levels, that result in small residuals of loss above background, are detectable because of the instrument's high resolution. We have used the resonator to examine loss spectroscopy of quartz resonators vibrating in flexure. The resonators have a largebackground loss that peaks up at low temperature. Although the peak very closely fits a Debye-like equation, the derived parameters, such as the decay time prefactor, are unphysical.
\end{abstract}

\section{INTRODUCTION}

If one attempts to measure a small change in loss in a mechanical resonator system in the presence of a relatively large background loss, then the problem of poor resolution of conventional techniques becomes apparent. We were faced with that issue in the process of measuring loss in flexure-driven quartz oscillators. Flexural quartz oscillators have relatively low $\mathrm{Q}$, about $10^{5}$, when compared to Q's of greater than $10^{6}$ that are normally seen in shear mode, overtone quartz resonators that are used for precision timing applications. Confronted by this problem, we have developed a new loss measurement technique that provides a thousand fold increase in loss resolution when compared to more conventional methods such as the impedance bridge technique. This paper describes the instrument and brings new insight to the source of loss in flexural quartz oscillators.

For many years, researchers have used internal friction spectroscopy to study a wide range of defects, such as substitutional impurities [1], interstitials [2], and dislocations [3]. It has also proven valuable for investigations of radiation damage [4], diffusion [5], and thermal processes [6]. Today there is a renewed interest in internal friction measurement techniques because of the discovery that the sensitivity and selectivity of chemical sensors are greatly enhanced by information from loss measurements. In addition, researchers have recently begun to use loss measurements in tribology to study atomic level interactions at interfaces between sliding surfaces [7]. However, the sensitivity of conventional techniques limits the resolution in these new applications.

Internal friction spectroscopy is based on the fact that defects absorb energy produced by external stresses and dissipate it as heat. A loss spectrum is made by measuring energy loss as a function of temperature while mechanically stressing a sample at a fixed frequency. Peaks appear in a spectrum when the relaxation time of a defect is comparable to the period of the applied stress. In order to make a loss measurement, a resonator is made to vibrate near a resonant frequency. In the case of quartz crystal resonators, the drive signal is delivered to metal electrodes deposited directly on the quartz. When the drive signal is shut off, the amplitude of the oscillations decreases due to energy dissipated by defects in the resonator. The loss per cycle is then determined from the decay rate of the vibration amplitude. A detector circuit measures the decay of the peak amplitude as a function of the number of cycles executed and the loss is calculated from the slope of a fit to the logarithm of the decay signal. We achieve extremely high sensitivity by means of a new envelope detector circuit and associated software. 


\section{NRL INTERNAL FRICTION SPECTROMETER}

Fig. 1 is a block diagram of the NRL high resolution loss spectrometer. A computer controls all operations of the instrument and performs data acquisition and analysis. Specimens are mounted in a vacuum cryostat and maintained at any temperature from $4 \mathrm{~K}$ to $600 \mathrm{~K}$, to within $\pm 1 \mathrm{mK}$. Signals from the resonator are amplified and fed to a digital detector circuit invented at NRL which, in turn, gates two counters. One counter determines the number of vibrations executed between each of a number of threshold amplitudes and the other records the elapsed time. Typically, $\sim 100$ threshold amplitude levels are set for each decay curve when loss is $-10^{-5}$; they are measured with four-place accuracy. A decay curve is taken about every three seconds; in that way we can track dynamically changing loss and increase statistics to improve resolution.

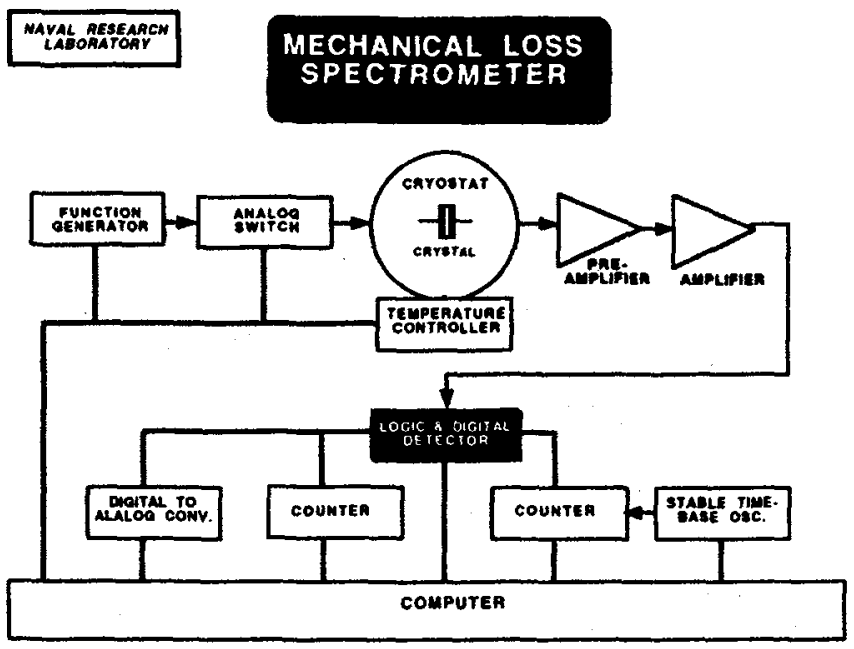

Figure 1: Block diagram of the internal friction spectrometer.

If a single relaxation process dominates the behavior of the decay, then the experimental data are indistinguishable from a least squares fit of the data (See Fig.2a.). Fig. 2b shows that experimental points differ from the theoretical curve by about one part in a thousand. Deviations above this indicate the presence of multiple relaxation phenomena. The multitude of points recorded along the decay curve allow us to observe, e.g., second-mode interference phenomena.
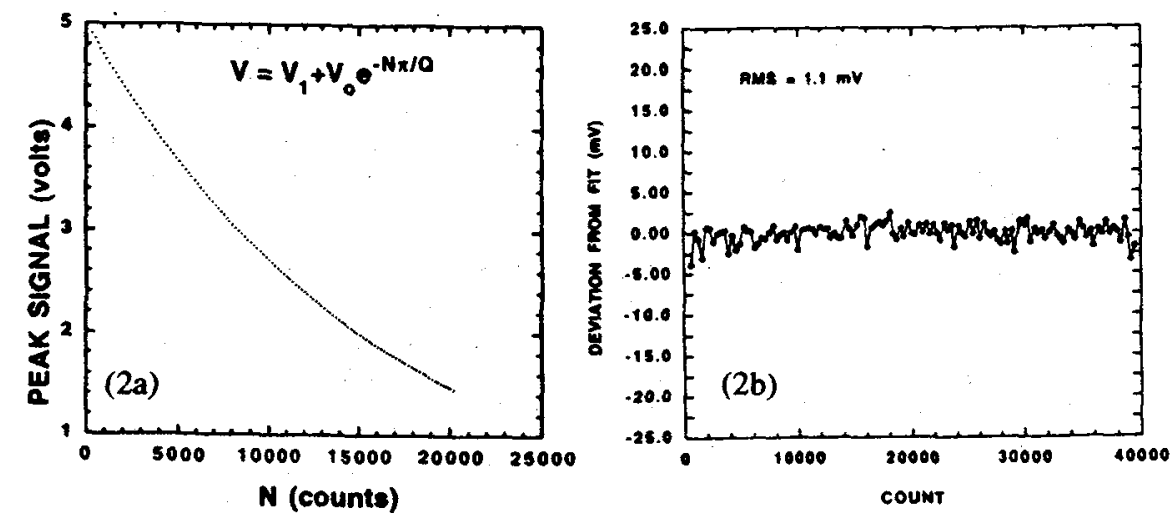

Figure 2: The decay curve of a single relaxation process. The data $(2 a)$ is fit by the simple exponential function that gives loss, $Q^{-1}$. The rms deviation from this fit is $-1 \mathrm{mV}(2 \mathrm{~b})$. 


\section{LOSS SPECTROSCOPY OF FLEXURAL QUARTZ RESONATORS}

The performance of the NRL loss spectrometer is illustrated by examining the loss of flexural quartz resonators. Fig. 3 shows a typical spectrum. The resonator is a tuning fork vibrating at $\sim 47.9 \mathrm{kHz}$. We have examined many flexural resonators and they all have a large low-temperature peak with a long, tail that extends up towards room temperature. One can make an excellent fit to this data with an equation given by De Batist [8]:

$\mathrm{S}_{0}$, the baseline loss $=7.83 \times 10^{-6} ; \mathrm{S}$, the relaxation prefactor $=1.13 \times 10^{-3} \mathrm{~K} ;$ to, the relaxation time prefactor $=8.45 \times 10^{-7} \mathrm{sec}$.; and $\mathrm{E}$, the activation energy $=3.47 \mathrm{meV}$. (A third term, important in the case of large amplitude vibrations, has been neglected.) The equation is similar to the standard Debye loss equation, except for the $1 / \mathrm{T}$ multiplier. If the loss peak is narrow, as is usually the case, this $1 / \mathrm{T}$ dependence is unimportant. We have no good physical model at this time that explains the parameters that arrive from this classical treatment of the loss process that is described by equation (1). The large relaxation time prefactor is particularly troublesome. It is obvious that this peak could have an impact on the loss of flexural resonators at room temperature.

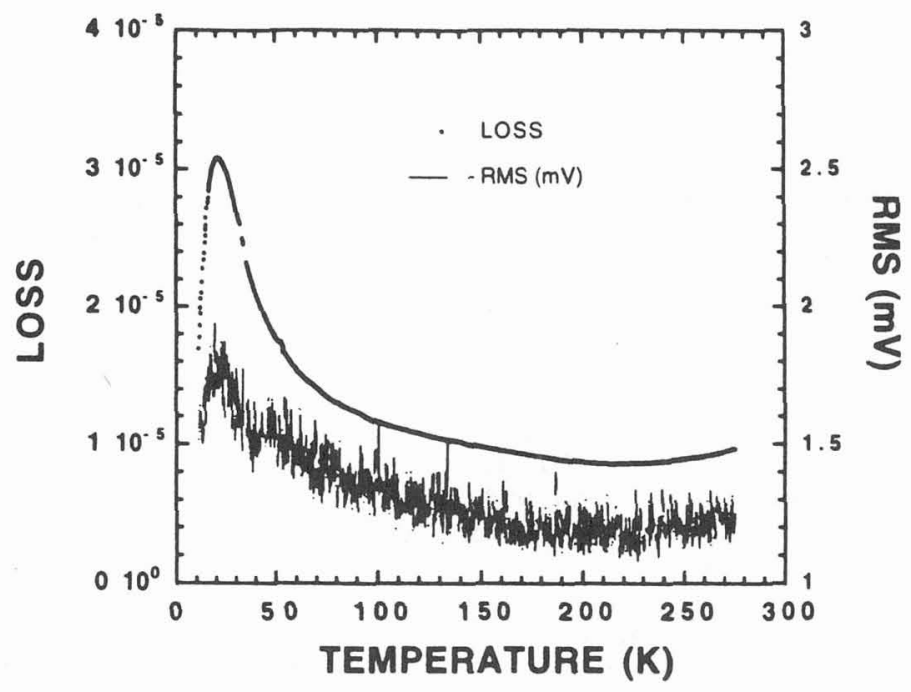

Figure 3: The loss of a $47.9 \mathrm{kHz}$ tuning fork resonator driven in flexure. The rms values refer to the deviation from a simple straight-line fit to the logarithm of the decay curve.

The ability of the spectrometer to measure deviations from a simple relaxation decay is also shown in Fig. 3. The data tracks the loss peak, suggesting that the low-temperature peak has a more complex decay associated with it, perhaps connected with third-order elastic constants. The classic phonon-phonon interaction treatment (the Akhieser effect) does not fit the data.

Fig. 4 further illustrates the power of the spectrometer. A background subtraction near $200 \mathrm{~K}$ to apparently featureless data similar to that of the tuning fork resonator, reveals a double-humped peak. One of the peaks (using standard internal friction modeling) is consistent with the $\mathrm{Ge} / \mathrm{Li} / \mathrm{e}$ - defect found in high purity quartz; the other peak is unknown. We estimate that some mechanically active defects in quartz are measurable to concentrations $\leq 10^{14} / \mathrm{cm}^{3}$ with this instrument. 


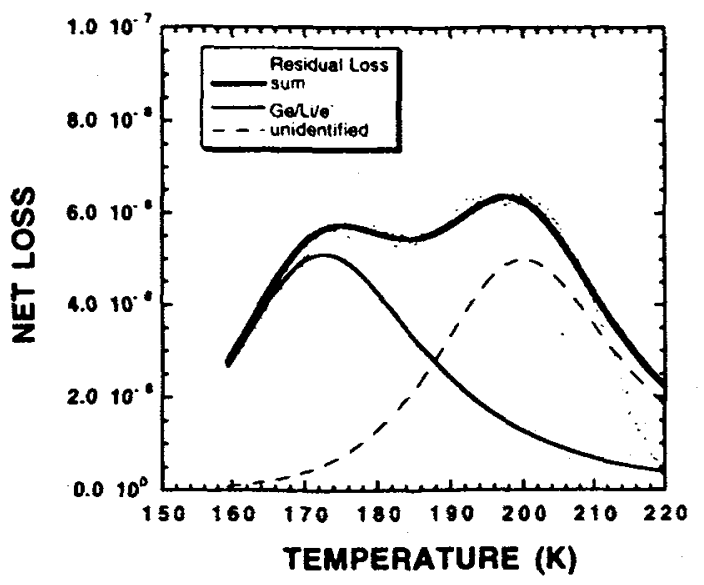

Figure 4: The residual loss of a flexural quartz resonator after subtraction of the featureless background. The doublehumped peak is fit with two internal friction peaks, one of which is consistent with the $\mathrm{Ge} / \mathrm{Li} / \mathrm{e}^{-}$defect.

We have perfected a high sensitivity internal friction spectrometer that opens the way to the study of a new range of defect densities and dynamical effects. For example, the time dependence of high temperature loss, measured at a number of temperatures well below the loss peak, will yield the activation energy of the peak without having to go to inaccessibly high temperatures. We have measured loss changes in quartz as small as $10^{-9}$ per hour using the new instrument. The study of such high activation energy relaxation processes provides a way to increase the understanding of long-term instabilities in quartz and other materials. Not only will the high sensitivity result in improved materials, but it may also serve as a basis for a new generation of ultra-sensitive chemical sensors.

\section{References}

[1] Bonjour C. and Benoit W., Acta Metallurgica 27 (1979), 1755.

[2] Berry B. S., J. Phys. Chem. Solids 31 (1970), 1827.

[3] Bordoni P. G., J. Acoust. Soc. America 26 (1954), 495.

[4] King J. C. and Sander H. H., IEEE Trans. Nucl. Sci. NS-19 (1972), 23.

[5] Snoek J. L., Physica 9 (1942), 862.

[6] Randall H. R., Rose F. C. and Zener C., Phys. Rev. 56, (1939) 343.

[7] Krim J. and Widon A., Phys. Rev. B 38, (1988-I) 12184.

[8] DeBatist, Internal Friction of Structural Defects in Crystalline Solids (North-Holland Publishing Co., 1972) 61 . 